\title{
Critical Issues in Leadership Development for Peer Support Specialists
}

\author{
G. Trey Jenkins ${ }^{1}\left[\right.$ D $\cdot$ Michael S. Shafer ${ }^{2} \cdot$ Nicole Janich $^{1}$
}

Received: 13 May 2019 / Accepted: 31 January 2020 / Published online: 7 February 2020

o) Springer Science+Business Media, LLC, part of Springer Nature 2020

\begin{abstract}
This paper is a qualitative analysis of perspectives on leadership development among working peer support specialists and highlights the challenges, needs and efficacy these individuals experience in their work settings. Six participants engaged in a $2 \mathrm{~h}$ semi-structured focus group. Participants were guided through a series of nine questions regarding their transition to leadership, professional communication and relationships. Seven themes emerged: managing dual relationships; having difficult conversations; push and pull of leadership; taking responsibility for others; taking responsibility for self-care; addressing stigma in the workplace, and, spirituality/a calling to help. These professionals integrate their personal experiences of recovery into their direct care and leadership approaches in the workplace. This blending of recovery concepts and supervision approaches reflect some of the powerful elements that peer recovery specialists are uniquely qualified to lead in the healthcare workforce. These findings provide important implications for leadership development among this growing segment of the healthcare workforce.
\end{abstract}

Keywords Peer support $\cdot$ Leadership $\cdot$ Supervision $\cdot$ Lived experience $\cdot$ Recovery

\section{Introduction}

Recovery-oriented services are becoming increasingly common in behavioral healthcare, particularly for individuals with serious mental illness (SMI) and co-occurring substance use disorders (Chinman et al. 2014; Gates and Akabas 2007). A recovery-orientation promotes whole health and focuses on self-directed care as individuals integrate into their communities (Gates and Akabas 2007). A recoveryorientation has prompted the rise of peer support as a core practice in behavioral healthcare (Chinman et al. 2014; Daniels et al. 2016; Gates and Akabas 2007). Many terms are

G. Trey Jenkins

g.trey.jenkins@asu.edu

Michael S. Shafer

Michael.Shafer@asu.edu

Nicole Janich

njanich@asu.edu

1 Arizona State University Center for Applied Behavioral Health Policy, 618 N. Central Ave Suite 100, Phoenix, AZ 85004, USA

2 Arizona State University School of Social Work, 304 N. Commerce Park Loop, Suite 250, Tucson 85745, USA used to describe individuals who provide peer support; this manuscript will use Peer Support Specialists (PSS).

Peer support is different from other forms of help provided by traditional behavioral health workers (Repper and Carter 2011). Peer support is a form of mutual aid provided by individuals, often certified, although not licensed, who are in recovery from mental illness and/or substance use. Peer support is based on mutuality, empowerment, hope and advocacy, and can be provided throughout treatment to facilitate long-term recovery and resiliency (Chinman et al. 2014; Gates and Akabas 2007). It involves giving and receiving help based on a shared understanding of what is helpful between people in similar situations (Soloman 2004; Mead et al. 2001). Respect, reciprocal relationships, empowerment, and shared responsibility are important concepts and practices in peer support (Repper and Carter 2011). PSS use their lived experiences-not professional expertise- to help individuals manage their mental illness, engage in treatment, and establish a fulfilling life (Chinman et al. 2014). PSS are uniquely positioned to instill hope through self-disclosure, to model self-care of mental illness, and to develop relationships based on trust, acceptance, and empathy (Davidson et al. 2012; Repper and Carter 2011). Research has shown that, when compared to traditional behavioral health services, people who 
engage in peer support, experience improved outcomes across various areas of health and wellbeing (Davidson et al. 2012; Chinman et al. 2014; Gates and Akabas 2007; Hutchinson et al. 2006; Repper and Carter 2011).

It is estimated that there are over 30,000 PSS working in the U.S. Approximately 40 states have certified peer programs with the average PSS making $\$ 15$ per hour (Kaufman et al. 2016; Daniels et al. 2016). PSS work in a variety of settings including inpatient and outpatient facilities, day treatment programs, hospice, respite, rehabilitation centers, and government organizations (Chinman et al. 2014). PSS can serve in a variety of roles, such as advocacy, navigation, outreach, case management, developing and facilitating treatment services/activities, mentoring, supervision, training, administration, and education (Salzer et al. 2010). PSS can also serve in a variety of settings including emergency rooms, hospitals, jails, prisons, state psychiatric hospitals (Cronise et al. 2016; Salzer et al. 2010, Migdole et al. 2011). A peer-run is a program that unlike traditional treatment models, is more focused on socialization, self-directed support, empowerment and hope (Swarbrick et al. 2009).

Individuals engaged in the profession of peer support have been shown to benefit from the experience in terms of enhanced self-esteem, empowerment, hope, coping skills, and community integration (Gates and Akabas 2007; Hutchinson et al. 2006; Repper and Carter 2011). PSS also benefit from increased income, increased sense of self-efficacy, and opportunities for skill development, socio-economic mobility, and career advancement (Gates and Akabas 2007; Hutchinson et al. 2006; Repper and Carter 2011). Self-efficacy is an important element in successful leadership. It is the perception that one is capable to meet the demands of a specific task (McCormick et al. 2002). It is this concept that influences leadership behaviors such as goal setting, decision-making, and problem solving. Literature on selfefficacy has demonstrated the causal relationship between self-efficacy and leadership success. Agency leadership has a great deal of influence in developing an individual's selfefficacy. Agency leaders can support increased self-efficacy by giving their supervisory staff challenging opportunities, modeling successful skills and strategies, and providing thoughtful feedback and encouragement (McCormick et al. 2002).

As integrated care becomes more prevalent and Medicaid reimbursements expand, PSS roles are expected to grow as well (Myrick and Del Vecchio 2016; Tucker et al. 2013; Swarbrick et al. 2011; 2013; Peers for Progress 2012). A challenge will be the professional development and career advancement opportunities available to PSS workers that allow them to expand their role, including leadership, while not diminishing the value of lived experience of recovery (Cronise et al 2016).
To date, little research has been reported on the leadership development of peer support specialists. Anecdotal evidence suggests that there are many peers already working in leadership and supervisory roles today (iNAPS 2014; Daniels et al 2016). There is a growing need to address leadership and supervision within the peer workforce in general, and more specifically, addressing the motivations and self-efficacy in peer leadership development. In this study, we explore some critical elements necessary for PSS career development and the transition to leadership. This is explored at both the intrapersonal (transition from client to peer and peer to leader) and the inter-personal (professional relationships and communication) level.

\section{Methods}

\section{Sampling}

A convenience sample comprised of six (6) PSS were recruited from a pool of thirteen (13) participants in a university-sponsored Peer Support Specialist leadership development program. Six (6) individuals chose not to participate in the focus group and one (1) individual dropped out of the program prior to focus group recruitment. The participants were invited to attend a statewide behavioral health conference where they presented their culminating project, attended a graduation for the leadership program, and participated in the focus group. The group included three female and three male participants. All but one of the participants currently works in a supervisory capacity. All but one participant are employed by a peer-run agency. One of the participants is in a leadership role, but has no direct supervisory responsibilities.

\section{Data Collection, Measures, Analysis}

The focus group was held in a small conference room where a university-sponsored behavioral health conference was occurring. Data was collected during a two-hour session that was facilitated by two researchers. The semi-structured focus group followed a protocol that provided narrative for facilitators to follow and guided participants through a series of questions and discussion topics (See Appendix). The session was audio-recorded and transcribed for analysis.

Drawing upon the foundations of mutual aid (Bergart 2015; Waskey 2007), recovery (Borkman et al. 2016; Kaskutas et al. 2015), and workforce development (Holland 2015; Jacobs and Hawley 2009), questions developed by the researchers were informed by the interpersonal and intrapersonal circumstances in leadership development. Participants were asked a variety of questions regarding their motivations to become a PSS, their transition to leadership (e.g. 
barriers, strengths, challenges), and professional relationships and communication (e.g. Who initiated the transition into a leadership role? How have things changed?).

The data was managed, coded, and analyzed using Nvivo Pro version 11. Themes were derived using an iterative approach in which coding was guided by theory, literature, and concepts that emerged naturally (Tracy 2013). We identified seven common themes defined in Table 1. The study was approved by Arizona State University's Institutional Review Board.

\section{Results}

\section{The Push and Pull of Leadership}

Participants described a number of internal and external factors that were associated with their movement into a leadership/supervisory role. We defined the "push and pull" of leadership as: Push - the expressions of internal or personal drive and desire to lead, to advance in one's career, and confidence in one's leadership potential. Pull-the expression of being recruited, targeted, encouraged or fast tracked into a leadership role. For example, balancing one's personal recovery and personal drive was described by one participant as:

I can say a few times, I was approached and offered the keys and I said, 'No, I don't think I'm ready for that yet.' I was in transition... there was a lot of programming, and parenting classes and things like that... .I didn't want that responsibility at that time. It was 2009 .... I was like, 'Yeah, I think I'm ready.' They offered me the keys again. I was like, 'Okay'.

Another participant described the pull from an employer who had faith in them, their recovery, and their abilities: "A lot of people had faith in me, and they were other people in recovery, and - they held the hope for me when I couldn't have the hope for myself maybe." Another participant described the push as: "That I'm capable, for me. Capable of being in a supervisory role and being successful in it."

\section{Managing Dual Relationships}

As part of the transition process, participants discussed the dynamics and challenges of going from co-worker/friend to leader/supervisor in their organization. Participants discussed the degree of distance they maintain with colleagues who are also peers in recovery. Some maintained close friendships, while others distanced themselves. One participant shared, "I'm very picky on who I really truly allow into my life and stuff like that because a lot of coworkers, they're peers, but they [are not] trying to do the same thing that I'm trying to do." The challenges of establishing appropriate workplace boundaries was characterized by another participant: "It's like, we can-like at lunch, we can talk about our families and stuff like that, but when we're at work and when we're in our supervisions and things like that, it's all about work. That's a challenge." Another participant described the deterioration of a relationship with their "best friend in recovery": "I'm still me. I'm just in a different role. I'm still peer support first, period. You had asked what's the relationship like now. It's nonexistent....We never talk anymore."

\section{Having Difficult Conversations}

Another theme that emerged from the participants' transcript was having difficult conversations. We defined this as comments that conveyed an ability to be assertive, give direction, listen with empathy, and provide constructive criticism. Some experienced challenges in assertiveness, and others struggled with giving direction. For example, "I think communication is huge. That is something I've struggled with; having difficult conversations..., sometimes being assertive, standing up for what I believe in." They went on to say:

Table 1 Definition of themes

Push and pull of leadership

Managing dual relationships

Having difficult conversations

Taking responsibility for others

Taking responsibility for self-care

Addressing stigma

Spirituality/a calling to help
Push - the expressions internal or personal drive and desire to lead, to advance in one's career, and confidence in one's leadership potential. Pull - the expression of being recruited, targeted, encouraged or fast tracked into a leadership role

Balancing the dynamics and challenges of going from co-worker/friend to leader in their organization. Appropriate peer and supervisor relationships with former co-workers/friends and the impact on recovery relationships

The ability to be assertive and give direction, listening with empathy, and constructive criticism

Expressions of responsibility for mentoring, supporting, coaching or modeling for staff and co-workers

Activities that aim to reduce compassion fatigue and burnout. The balance of professionalism and addressing stigma in the workplace

Experiencing bias and/or advocating against bias. Modeling what it means to be a peer professional

Reference to higher power, God, spirituality, which often intersects with religiosity and/or intersecting with a calling to help or become a PSS 
I'll let somebody keep making the same mistake because I won't say anything. They shoot the messenger, right? Who am I to tell them how to do it if they want to keep doing it the wrong way? I should. Deep down inside, I know I should. I just don't want the pushback, so I just don't say anything.

Participants also described difficulty in providing constructive criticism. "I've never seen an organization of workers where you say one thing, and it messes up their whole day, and they want to go home." Another participant described using what they called "praise-polish-praise," or more commonly known as a praise sandwich, a concept learned in their initial peer support certification training (St. George 2019). They went on to describe the praise method of communicating; "for me, I would rather a peer tell me, 'Hey, I'm noticing this. What's that about?' Because then... I'm not receiving it as a, you screwed up kind of thing".

Another participant went on to discuss the challenge of active listening and expressing empathy when communicating.

Learning to listen and being empathetic no matter what. That's been the biggest one for me [because] sometimes you do have the right answer for them..., but that's not what they really need to be hearing. They just need to be heard....

With regard to difficult conversations, we asked a follow up question about strengths and challenges communicating with peers versus non-peers at work. One person shared their thoughts on talking with non-peers:

For me, it's been nice because I don't always have to talk recovery. I can just have a normal conversation, which in recovery, is normal conversation for me, but always talking about mental health or always talking about substance use....I can actually talk about something else now, too.

Conversely, another participant, who works at a Consumer Operated Service Program, described the ability to talk openly about their recovery and how healing it was to be open about their diagnosis and work with other peers:

The reason why I like working for...is because I don't have to deal with that....I kept a secret for so long at a company that I didn't want them to know, and all it did was hurt me....I don't want to go down that path again.

\section{Taking Responsibility for Others}

Taking responsibility for others was another theme that emerged from the transcript and included expressions of responsibility for mentoring, supporting, coaching, or modeling for staff and co-workers. One participant characterized the responsibility as: "You guide, but you can't do it for them." Participants recounted instances where they offered coaching that promoted self-sufficiency and empowered staff.

Why are you [supervisee] dropping this at my door? This is where I show you how to do what I can do..., so that we all are on the same page, and we all learn to do what I can do so that [we are] stronger together.

Unique to peer supervision, is supporting staff's recovery as it relates to their profession and role. This is a delicate balance of supportive supervision and empowering the PSS, while not becoming the "therapist or sponsor". One participant described their feelings of working with a staff member who experienced a relapse:

When they don't understand, why does this keep happening to me? It's like, [because] you're still high. You want to tell them like that, but you can't—-they have the answers themselves, so you can't really tell them. You can. You do tell them, but you don't really-you have to tell them in a way that they get it for themselves.

\section{Taking Responsibility for Self-care}

Self-care was a common topic of conversation among these participants. The self-reflection and self-awareness of PSS regarding their own self-care is a unique asset of this workforce. For many, self-care is important to sustaining recovery, especially as responsibilities increase. One participant described the experience of how they took control of their depression symptoms:

... For me, it was depression....I can allow that to get out of control if I allow it to, but I'm able to now recognize and try to not take my work home with me and really focus more on taking care of myself when I'm not actually at work.

Another participant reflected on self-care, and how it helped them prepare to lead. "Having new responsibilities, I realized, I need to get a full night's sleep. I need to actually exercise again and get in the right mindset for this." In addition to sleep, meditation was a frequently identified self-care tool:

The other thing is the meditation part. I know how important meditation is. I really do. I need that quiet time. Now, I'm actually doing the meditation. I'm actually doing it. More formalized as opposed to just sitting in the corner and reading my affirmations, the breathing exercises. It really helps.

One participant described incorporating meditation into her leadership and supervision strategies: 
I started doing a meditation for my staff. I just put it on my phone, and it was like at 1:00. That's it. We're locking the door. We're gonna put a note up. If you want to participate, great. If you don't, that's great too.

\section{Addressing Stigma in the Workplace}

Commonly addressed in peer support is stigma and the role peers have in advocating for others with mental illness and on behalf of themselves as peer professionals. Stigma in the workplace can be a huge stressor; part of caring for self is to address stigma in a manner that fits the individual. In a follow up question, participants shared how they addressed stigma in their respective agencies. Participants described their experience as either witnessing bias (personally or secondary) and/or advocating against bias. One participant shared their experience of witnessing co-workers talk negatively about a fellow peer:

We had another-a peer, an admin, and just she was going through a hard time in her recovery. She was having some struggles. Just to hear some of the ways that other people would talk about her and being a peer, I felt this, 'I got to stick up for her.' You know what I mean? It sucked because you see this side of people, and you're like, don't you have any empathy? Haven't you been through some hard times? Maybe you don't talk about it, and maybe you're not as open to sharing about it with other people, but it's like, it's hard to see that.

They went on to say that they felt challenged to "step up" and advocate, but they felt a responsibility to not only advocate for this one individual, but to "help promote what a peer is really [and] how recovery is...normal." Another participant described their feelings about advocacy in the workplace as a peer professional:

That was a growing experience because I figured out that I'm still able to advocate and still remain professional, and at the same time, I didn't care about what that person thought about me later because it's like, as a peer, if I'm not doing that, then I'm adding to the stigma, or I'm - not adding to it, but I'm not contributing to stopping it either.

\section{Spirituality/A Calling to Help}

For many of the participants, their spirituality is a foundational element of their recovery and one which fuels the passion for their work. For those individuals in recovery that have participated in some form of 12-step group (Alcoholics Anonymous, Narcotics Anonymous), the 12th step's call to service provides a spiritual basis for their work in the recovery field. "Having had a spiritual awakening as a result of these steps, we tried to carry this message to alcoholics and to practice these principles in all of our affairs" (Alcoholics Anonymous 2001). As one participant described a common expression among PSS: "I fell into it, but deep down inside, I've always known that I wanted a job helping others that are recovering from substance abuse ever since I went into treatment." For others, their early recovery experiences were religious-based and involved an intentional decision to convert: "When I first got into recovery about five and a half years ago, I got saved. I'm all about God and church and stuff like that." Another participant characterized their leadership as divinely inspired: "My higher power, which is God and Jesus Christ....I realized at that point in time that everything that I'd done in the past was preparing me for this position."

\section{Discussion}

The purpose of this study was to identify common experiences of PSS who have advanced in their career to a supervisory or managerial role. A focus group of six PSS working in managerial/supervisory roles in outpatient behavioral health agencies was conducted with the resulting audio recording transcribed and qualitatively analyzed. Seven recurring themes emerged that characterized some of the experiences and resulting insights these individuals disclosed. These themes provide insight for the leadership development of PSS, along with implications for health care agency peer support program development.

Before exploring the effects of these findings, we acknowledge the significant limitations of our methods and the resulting limitations to the external validity of these findings. The small sample size and single sample is a significant limiting factor. In spite of this limitation, the results provide some tentative observations that may advance the research and development of this unique and growing segment of the healthcare workforce.

\section{Practice Implications}

These findings provide support for agencies that are employing PSS and/or responsible for the cultivation of professional and leadership development. Our findings suggest that communication in general, and effective management of difficult conversations in particular, may be areas for training and development in PSS managers, and other staff as well. The participants of this focus group discussed the importance of having direct and 'difficult' conversations with staff while at the same time, expressing a range of efficacy in doing so. For these participants, personal experiences in receiving 
and providing direct communication to others often creates an awareness of the importance of such communication. Experience in group therapy, individual therapy, and wellstructured 12-step meetings provide unique but consistent exposure to direct communication, often about one's own shortcomings, sobriety status, symptom status, and substance use. As such, these emerging leaders may have a sense of comfort in these sorts of communications. Providing these emerging leaders with learning opportunities about how to have direct workplace communications may be a practice agencies should consider.

Another practice implication for agencies is the value in addressing the challenges and strategies of managing dual relationships with their former co-workers and/or "recovery buddy". Dual relationships, where the peer professional has more than one relationship with clients or colleagues (Reamer 2003), are something the peer leader will inevitably have to manage. For the individual, they may decide to maintain their friendships, and for others it is important to impose a personal policy of no friendships in the workplace. What is important is that new leaders have the ability to discern when to be supportive, and when to refer their staff to outside support. It is a delicate balance when trying to maintain the essence of peer support and mutuality. Agencies developing PSS leaders may wish to consider creating opportunities for emerging leaders to have on-going conversations around supervision and boundaries. Within larger agencies, physically re-assigning leaders to new locations where they have not previously worked as a PSS may be an option to consider in certain circumstances. Additionally, peer supervisors are important for early career peer professionals and peer support teams who need guidance and mentorship through the lens of peer support and recovery principles.

Managing dual relationships is not unique to PSS leaders, it has been noted as a leadership concern and consideration among non-PSS emerging leaders as well (Reamer 2003). The individuals that participated in this study expressed a range of strategies and approaches they take in managing these relationships in an effective, recovery-informed approach. Once again, the lived experience of recovery that these individuals have shared often leads to a greater sense of self and self-awareness. This sense of self, often a focus of therapeutic interventions, results in individuals developing greater clarity in their interpersonal boundaries.

The participants described the importance of self-care and their responsibility to use self-care to be a better leader. Participants described the need to get a good night's sleep, eat well, and create a wellness routine that supports their own recovery and leadership capability. One participant described their efficacy in taking control of their symptoms in order to meet the demand of their increased responsibilities. The lived experience of PSS may uniquely prepare them to be "organizational champions" (Valente 2008) within an agency looking to stimulate workplace wellness initiatives among their staff.

One of the more unique aspects of employees with lived experience is a robust presence of spirituality that the employee assigns as their reason for working as a PSS. As noted by Deegan (2004), recovery from mental illness is in part a spiritual experience. For individuals exposed to 12 -step recovery programs, spirituality and a calling to help are central themes and concepts. Culminating with the 11th and 12th step acknowledgement of a 'spiritual awakening', and a commitment to spread the word of recovery, becomes a call to action for many individuals to enter helping professions such as peer support. This spiritual element has important practice implications for both PSS leaders but also agencies developing PSS leaders. For leaders, developing a spiritual foundation is an intrapersonal exploration that can enhance emotional intelligence (Bracket et al. 2011; Serrat 2017) which are an important set of soft skills that are highly coveted in today's leaders. Incorporating a spiritual foundation while transitioning to a leadership role, is a critical time that may be supported by supervisors and mentors of emerging PSS leaders. In particular, PSS may need structed time to discuss how to incorporate spirituality as a foundation to their values, beliefs, and sense of self, without bringing spirituality/religion as a primary feature in their professional role.

As noted, these findings are limited by our methodology and sample size. Nonetheless, we believe that the concepts that emerged from this focus group provide a framework that will contribute to future research on peer leadership development in the healthcare workforce. The recent release of practice-guidelines for peer specialists and supervisors by the The International Association of Peer Supporters (iNAPS 2019) provides a framework for peer specialist-supervisors, closely aligning with some of the peer leadership qualities addressed by the current study. Future research should elaborate upon the 'hard skills' or technical-administrative skills and competencies that emerging peer supporter leaders are called upon to develop (Zimmerman-Oster and Burkhardt 2000). Skills such as reading financial ledgers, budgeting, project management, proposal development, and data driven decision-making are a few of the universal leadership skills that emerging PSS leaders may need to acquire. Future research should assess the competency and efficacy of PSS leaders in these technical areas. Integrating high priority skill training into existing PSS academies and other educational opportunities for PSS workers could advance the development and achievement of this segment of the workforce.

Further research on emerging PSS leaders should more deeply explore the experiences of workplace stigma and discrimination. Although stigma was not a major theme among 
these participants, it lingered below the surface and may have been minimized by the over-representation of Peerrun agency based participants in this study. Future research should also draw upon larger and more representative samples of emerging PSS leaders, particularly those who are employed in hospitals, outpatient healthcare and/or behavioral healthcare agencies. In these agencies, managed by and staffed predominately by non-PSS staff, anecdotal reports of bias and stigma by PSS employees are not uncommon and undocumented. Research that more accurately assesses the prevalence of workplace stigma and identifies organizational strategies that reduce or eliminate stigma, is critical to the continuing development of the peer workforce.

\section{Appendix}

\section{Leadership \& Supervision Focus Group Questions}

\section{Introduction to Focus Group}

First off, congratulations on completing the Leadership and Supervision course and thank you all for participating in today's focus group. My name is Trey Jenkins and this is Nicole Janich. We will be facilitating today's discussion.

\section{Why Are we Conducting Today's Session?}

To learn more about your individual experiences working as a peer in a leadership role.

Additionally, there is a gap in research regarding peers in leadership and it is our goal to write and publish a paper based on your experiences in the course and today's discussion.

\section{To Give you an Idea About how the Focus Group will Proceed, we would like to go over the General Structure and Guidelines}

During the activity, we are going to ask a number of questions designed to get a picture of your experiences working as a peer in leadership.

We will ask questions in two broad categories including, intrapersonal (self/internal) and interpersonal (relationships with colleagues and staff both peer and non-peer), Feel free to share your thoughts and feelings openly. All results and future discussion will be anonymized.

Please know that there is no right or wrong answers to any questions. We are interested in your honest experiences and opinions.

Our session will be audio-recorded so that we can go back and listen to them later. Please speak one at a time and think about the recording and me taking notes as simply an extension of my memory. If you are uncomfortable being recorded, you may leave the room at any time.

We will keep your comments confidential and your names will not be associated with any reports.

\section{Process for Focus Group Discussions}

We have a series of questions. we will ask a question to prompt a discussion, invite you all to discuss, and ask follow up questions if necessary.

We invite you to talk with each other.

Sometimes, I may jump back into the conversation and direct it to go another way.

Today, we have scheduled two hours for the discussion. We may or may not use the entire amount.

Are there any questions before we begin?

\section{OPENING}

To get started we would like to begin with everyone introducing themselves and tell us how many years you have been working as a PSS and when you transitioned to a leadership role. By leadership role, we generally think of someone who is supervising or guiding other individuals and/or making decisions or contributing to the decision making process for an organization or program. How many of you are working in a leadership role such as that which I just described?

\section{QUESTIONS}

\section{Intrapersonal}

Transition from Peer to Leader: Next, we would like each of you to please describe your personal experience in peer support.

1. People become interested in working as peer support specialists for a variety of reasons and motives. Tell me about some of the reasons or motives that each of you had that lead you into this line of work.

a. Had you worked in a helping profession before becoming a peer support specialist?

b. How long did you work as a peer support specialist?

2. In order to participate in the leadership course, each of you had to document that you are currently, or are about to be promoted into a leadership role within your agency. Tell me about the circumstances under which you transitioned from a worker role to a leadership role?

a. Had you sought this out, or did someone in the company approach you? 
b. How would you describe the feelings or emotions you experienced at the time that this transition opportunity was presented to you? (cues: Nervous? Confident? Excited? Scared?)

c. How long after you had been promoted to a leadership role was it before you began to feel confident in your new role? In what capacities in this new role do you feel more confident? Less confident?

3. Thinking only about your own health, emotions, recovery, knowledge and skills, what are some of the challenges and barriers that you experienced as you transitioned into this new role?

a. What are some of the challengers \& barriers you continue to struggle with?

4. Thinking only about your own health, emotions, recovery, knowledge and skills, what have been some of your personal areas of growth and development?

a. What have you learned about yourself that you didn't know before?

b. What areas of personal growth and development do you still hope to realize?

c. In what ways have you surprised yourself?

\section{Interpersonal}

Professional Relationships and Communication: Moving into a leadership role often brings about changes in how we relate to others, including our partners, family members, coworkers, and others in leadership positions. I want to turn our attention now to your interpersonal interactions, both inside and outside of the workplace.

1. Sometimes when we get promoted into a leadership role, we find ourselves now supervising or directing the work of former coworkers. By a show of hands, how many of you have or are now supervising people who used to be your coworkers?

a. What was that experience like for you during the first few months after your promotion?

b. How would you describe the nature of those relationships now?

c. What did you and your former coworkers do to improve these types of relationships, or what would you recommend other do who find themselves in these situations?

2. When we get promoted into a leadership position, we find ourselves developing a whole new set of peer relationships, or adjusting the nature of our relationships with other individuals who are also in a leadership role. By a show of hands, how many of you have had to develop relationships with new coworkers or supervisors as a result of your promotion? By a show of hands, how many of you find yourself working now with coworkers who are not in recovery? Exclusively (all coworkers not in recovery?) (all coworkers in recovery?) (a mix of coworkers?)

a. What was that experience like for you during the first few months after your promotion?

b. How would you describe the nature of those relationships now?

c. What did you and your new set of coworkers or supervisors do to improve these types of relationships, or what would you recommend to others who find themselves in these situations?

d. How has your former status as a peer support specialist (or knowledge of recovery status) affected these relationships?

i. Do you feel that you are treated differently because your coworkers know you are in recovery?

ii. Describe the nature of that different treatment?

1. Probe: Coddled? Excluded from meetings, discussions, decision making opportunities? Treated with "kid gloves"? Performance expectations that were less than or more than others? Disrespected?

iii. What did you and your former coworkers do to improve these types of relationships, or what would you recommend others do who find themselves in these situations?

e. How would you compare the nature and quality of the relationships you have with your coworkers who are also in positions of leadership, as compared with your coworkers when you were a peer support specialist?

i. Probe: More professional; less personal; more task oriented; more guarded; less supportive

3. Thinking only about the interpersonal interactions you have with your former and your current coworkers and supervisors, what are some of the challenges and barriers that you experienced as you transitioned into this new role?

a. What are some of the challengers \& barriers you continue to struggle with?

4. Thinking only about the interpersonal interactions you have with your former and your current coworkers and supervisors, what have been some of your personal areas of growth and development?

a. What have you learned about yourself that you didn't know before? 

b. What areas of personal growth and development do you still hope to realize?
c. In what ways have you surprised yourself?

\section{Ending Question and Wrap up}

1. Is there anything we have not discussed that you would like to mention?

Thank you all for participating in our discussion today. If you have any questions regarding the focus group that we did not cover today, please contact us by email or phone (Facilitators provide their business cards to participants).

\section{References}

Anonymous, A. (2001). The Story of how many thousands of men and women have recovered from alcoholism (4th ed.). New York: AA World Services Inc.

Bergart, A. M. (2015). Introduction to part two: What is a group, and what is social work with groups? Social Work with Groups, 38(34), 234-237. https://doi.org/10.1080/01609513.2014.951302.

Borkman, T. J., Stunz, A., \& Kaskutas, L. A. (2016). Developing an experiential definition of recovery: Participatory research with recovering substance abusers from multiple pathways. Substance Use \& Misuse, 51(9), 1116-1129. https://doi.org/10.3109/10826 084.2016.1160119.

Brackett, M. A., Rivers, S. E., \& Salovey, P. (2011). Emotional intelligence: implications for personal, social, academic, and workplace success: Emotional intelligence. Social and Personality Psychology Compass, 5(1), 88-103. https://doi.org/10.111 1/j.1751-9004.2010.00334.x.

Chinman, M., George, P., Dougherty, R. H., Daniels, A. S., Ghose, S. S., Swift, A., et al. (2014). Peer support services for individuals with serious mental illnesses: Assessing the evidence. Psychiatric Services, 65(4), 429-441. https://doi.org/10.1176/appi.ps.20130 0244.

Cronise, R., Teixeira, C., Rogers, E. S., \& Harrington, S. (2016). The peer support workforce: Results of a national survey. Psychiatric Rehabilitation Journal, 39(3), 211-221. https://doi.org/10.1037/ prj0000222.

Daniels, A. S., Ashenden, P., Goodale, L., Stevens, T. (2016). National Survey of Compensation among Peer Support Specialists. The College for Behavioral Health Leadership, www.leaders4health. org.

Davidson, L., Bellamy, C., Guy, K., \& Miller, R. (2012). Peer support among persons with severe mental illnesses: a review of evidence and experience. World Psychiatry, 11(2), 123-128.

Deegan, P. (2004). Spiritual lessons in recovery. Retrieved from https:// www.patdeegan.com/blog/posts/spiritual-lessons-recovery

Gates, L. B., \& Akabas, S. H. (2007). Developing strategies to integrate peer providers into the staff of mental health agencies. Administrative Policy in Mental Health and Mental Health Services Research, 32, 293-306. https://doi.org/10.1007/s 1048 8-006-0109-4.

Holland, B. (2015). A workforce development systems model for unemployed job seekers. Journal of Adult and Continuing Education, 21(2), 55-76. https://doi.org/10.7227/JACE.21.2.5.

Hutchinson, D. S., Anthony, W. A., Ashcraft, L., Johnson, E., Dunn, E. C., Lyass, A., et al. (2006). The personal and vocational impact of training and employing people with psychiatric disabilities as providers. Psychiatric Rehabilitation Journal, 29, 205. https://doi.org/10.2975/29.2006.205.213.

International Association of Peer Supporters (iNAPS). (2014). Report on U.S. peer support provider levels of education, compensation, and satisfaction a comparison between 2007 and 2014. Accessed April 21, 2016 from https://inaops.org/2014survey-of-education-compensation-and-satisfaction/

International Association of Peer Supporters (iNAPS). (2019). National practice guidelines for peer supporters and supervisors. Retrieved from https://www.inaops.org/supervision

Jacobs, R. L., \& Hawley, J. D. (2009). The emergence of 'Workforce Development': Definition, conceptual boundaries and implications. In R. Maclean \& D. Wilson (Eds.), International handbook of education for the changing world of work: Bridging academic and vocational learning (pp. 2537-2552). Dordrecht: Springer.

Kaskutas, L. A., Witbrodt, J., \& Grella, C. E. (2015). Recovery definitions: Do they change? Drug and Alcohol Dependence, 154, 85-92. https://doi.org/10.1016/j.drugalcdep.2015.06.021.

Kaufman, L., Kuhn, W., Stevens Manser, S. (2016). Peer specialist training and certification programs: A National Overview. Texas Institute for Excellence in Mental Health, School of Social Work, University of Texas at Austin.

McCormick, M. J., Tanguma, J., \& Lopez-Forment, A. S. (2002). Extending self-efficacy to leadership: A review and empirical test. Journal of Leadership Education, 1, 34-49.

Mead, S., Hilton, D., \& Curtis, L. (2001). Peer support: A theoretical perspective. Psychiatric Rehabilitation Journal, 25, 134-141.

Migdole, S., Tondora, J., Silva, M. A., Barry, A. D., Milligan, J. C., Mattison, E., Rutledge, W., Powsner, S. (2011). Exploring new frontiers: Recovery oriented peer support programming in a psychiatric ED. American Journal of Psychiatric Rehabilitation, 14(1), 1-12. https://doi.org/10.1080/15487768.2011.546274

Myrick, K., \& del Vecchio, P. (2016). Peer support services in the behavioral health workforce: State of the field. Psychiactric Rehabilitation Journal, 39(3), 197-203.

Peers for Progress. (2012, July 30). The Affordable Care Act and peer support [Blog post]. Retrieved from https://peersforprogress.org/ pfp_blog/the-affordable-care-act-and-peer-support/

Reamer, F. G. (2003). Boundary issues in social work: managing dual relationships. Social Work, 48, 121-133. Retrieved from https:// www.bu.edu/ssw/files/2017/07/Reamer-F.-Boundary-Issues-inSocial-Work-Managing-dual-relationships.pdf

Repper, J., \& Carter, T. (2011). A review of the literature on peer support in mental health services. Journal of Mental Health, 20, 392-411. https://doi.org/10.3109/09638237.2011.583947.

Salzer, M. S., Schwenk, E., \& Brusilovskiy, E. (2010). Certified peer specialist roles and activities: Results from a national survey. Psychiatric Services, 61, 520-523. https://doi.org/10.1176/ ps.2010.61.5.520.

Serrat, O. (2017). Understanding and developing emotional intelligence. In O. Serrat (Ed.), Knowledge solutions: Tools, methods, and approaches to drive organizational performance (pp. 329339). Singapore: Springer.

Solomon, P. (2004). Peer support/peer provided services underlying processes, benefits, and critical ingredients. Psychiatric Rehabilitation Journal, 27, 392-401. https://doi. org/10.2975/27.2004.392.401.

St. George, L., Rider, A., Zeeb, M., Smithers, T., Long, M., (2019). 6th Edition Peer Employment Training: A Certified Peer Support/ Recovery Support Specialist Training. RI International, Phoenix.

Swarbrick, M. A. (2013). Integrated care: Wellness-oriented peer approaches: A key ingredient for integrated care. Psychiatric Services, 64, 723-726. https://doi.org/10.1176/appi.ps.201300144.

Swarbrick, M., Schmidt, L. T., \& Pratt, C. W. (2009). Consumeroperated self-help centers: Environment, empowerment, and 
satisfaction. Journal of Psychosocial Nursing \& Mental Health Services, 47(7), 40-47.

Swarbrick, M., Murphy, A. A., Zechner, M., Spagnolo, A. B., \& Gill, K. J. (2011). Wellness coaching: A new role for peers. Psychiatric Rehabilitation Journal, 34, 328-331. https://doi. org/10.2975/34.4.2011.328.331.

Tracy, S. J. (2013). Qualitative research methods: Collecting evidence, crafting analysis, communicating impact. Chichester, UK: Wiley-Blackwell.

Tucker, S. J., Tiegreen, J., Toole, J., Banathy, J., Mulloy, D., \& Swarbrick, M. (2013). Supervisor guide: Peer support and whole health and wellness coach. Decatur, GA: Georgia Mental Health Consumer Network.

Valente, T., \& Pumpuang, P. (2008). Identifying opinion leaders to promote behavior change. Health education \& behavior, 34, 881896. https://doi.org/10.1177/1090198106297855.
Waskey, A. J. (2007). Mutual aid. Encyclopedia of Environment and Society (pp. 1184-1184). Thousand Oaks: Sage Publications.

Zimmerman-Oster, K., Burkhardt, J. C. (2000). Leadership in the making: impact and insights from leadership development programs in U.S. colleges and universities. Executive Summary. Kellogg Foundation. Battle Creek, MI. Retrieved from https://files.eric. ed.gov/fulltext/ED446577.pdf

Publisher's Note Springer Nature remains neutral with regard to jurisdictional claims in published maps and institutional affiliations. 